\title{
XLIII. On volta electricity of metals
}

\author{
J. Erskine-Murray D.Sc. F.R.S.E.
}

To cite this article: J. Erskine-Murray D.Sc. F.R.S.E. (1898) XLIII. On volta electricity of metals , Philosophical Magazine Series 5, 45:276, 398-432, DOI: 10.1080/14786449808621148

To link to this article: http://dx.doi.org/10.1080/14786449808621148

$$
\text { 曲 Published online: } 08 \text { May } 2009 .
$$

Submit your article to this journal

LII Article views: 2

Q View related articles ¿ 
XLIII. On Volta Electricity of Metals. By J. ErskineMuray, D.Sc., F.R.S.E., Heriot-Watt College*.

\author{
I. Introductory. \\ II. Method of Experiment. \\ III. Effects of Different Methods of Cleansiny the Motallic Surfaces. \\ IV. Thin Solid Films of Oxides, Iodidea, \&e. \\ V. Atmospheric or Time Effects. \\ VI. Very Thin Liquid Surface-Films on Metals. \\ VII. Thick Liquid-Films on Metals. \\ VIII. Films Formed from Gases. \\ IX. Temperature Variations. \\ X. Elimination of Metal-Air Potentials by Solid Nonconducting \\ Films on the Metallic Surfaces.
}

\title{
I. Introductory.
}

§. 1. THE experimental investigation described in this communication had as its primary object the elucidation and measurement of the variations of volta contact electricity of a pair of conductors, due to changes in the state of that portion of the surface of each conductor which was separated from the other conductor by an insulating medium.

$\S 2$. The discovery of contact electricity of dry metals in nir by Volta at the beginning of the present century, extended a quarter of a century later by Pfaff to dry varnished metals in other gases, has been confirmed by many subsequent experimenters. The reality of the electrostatic force in air near an interface between copper and zinc, inferred as an obvious consequence from it by Lord Kelvin, was experimentally demonstrated by him in $1861 \uparrow$. In the next twenty years many investigations were made, the more important being those of Hankel, Gerland, Clifton, Ayrton and Perry, and von Zahn. In 1881 a paper of great importance was published by M. Pellatt, and as the present paper is, in some respects, only an amplification and extension of his work, it may be of advantage to give a short résumé of it before going further.

M. Pellat's most important results appear to be (1) his demonstration of the influence of the physical condition of the metallic surfaces on their volta-potential; thus he found that a sharply scratched plate is positive to a more smoothly polished one of the same metal, the metals being washed with alcohol after polishing in both cases and allowed to dry before the measurement of their potential : (2) his measurements of

* Communicated by Jord Kelvin.

† Electrostatics and Magnetism, $\$ 400$ et seq.

$\ddagger$ Ann. de Chimie et de Physique, 1881. 
the temporary variations of potential due to change of temperature of a copper, iron, or zine plate: and (3) his experiments which prove the smallness of the changes produced in the potential-difference of eopper and zine by varying either the pressure or the nature of the gas surrounding them.

$\$ 2 a$. I shall now give a short summary of the results detailed in the present paper :-

(a) Metals covered with nonconducting solid films of wax or glass, except at their point of contact, give nearly the same potential as the bare metals in air. The substitution of wax for air next the metal only causes a small change which may be in the same direction and of approximately equal amounts for metals whose potentials in air are very different; e.g. the volta-potential-difference between zinc and copper when both are coated with solid paraffin-wax is very nearly the same as that between bare zinc and copper. In this connexion I may mention that I have measured the potential of sodium coated with wax and glass, and find it to be abont 3.56 volts positive to a standard gold plate (see Chap. X.).

(b) A metal, cleaned by careful polishing and scratching with emery-cloth or glass-paper is less positive when its surface is in a sharply scratched condition than when smoothed or burnished, the difference frequently amounting to 2 or ' 3 of a volt. This result is not in opposition to that of M. Pellat, mentioned above, $\$ 2(1)$, for the conditions were different, as his plates were washed with alcohol after polishing while mine were not (see Chap. III, and also $\$ \S 39$ et seg.).

(c) The temperature variations, between $15^{\circ} \mathrm{C}$. and $60^{\circ} \mathrm{C}$, of the volta-potential of many metals have been determined, both for clean dry metals in air and for metals coated with liquid or nonconducting solid films ; and it has been found that they are of considerable magnitude in both cases. The curves representing the variation of potential with temperature appear as if they should meet at a point below $-200^{\circ} \mathrm{C}$., at a potential about 4 volt positive to a standard gold plate at, $16^{\circ} \mathrm{C}$.; this suggests that voita-potential-differences may possibly vanish at a very low temperature (see Chap. IX.).

(d) A liquid film, even if of extreme thinness, may cause a considerable change in the potential of a dry polished plate which continues permanent tor many hours and even days afier the disappearance of the film.

Two films of the same liquid opposed to one another on the surfaces of two plates of different metals do not usually give zero potential-difference, as solid conducting films of one material would do, but give nearly the same potential2 E 2 
difference as the dry metals on which they lie (see Chaps. VI: and VII.).

(e) A very thin film of oxide on a metal produces only a very small change in the potential, and every increase in thickness of the film is attended by a further change in potential until a limiting value is reached, which is that of a mass of the oxide (see Chap. IV.).

(f) Exposure to the atmosphere at ordinary temperatures does not as a rule produce any rapid change in rolta-potential, especially if the air be comparatively dry and free from dust. The ultimate change is usually in the negative direction (see Chap. V.).

(g) I have extended Lord Kelvin's experimants on the effect of temporary immersion of a metal in a gas to the cases of copper, zinc, tin, and silver in oxygen, and find that copper, zine, and silver become temporarily positive, while tin becomes negative in consequence of this treatment (see (hap. VIII.).

The research, suggested by Lord Kelvin, was carried out in the Natural Philosophy Laboratory of Glasgow University during the Sessions 1893-91-95, and during 1895-96 in the Cavendish Laboratory of Cambridge University. My thanks are due to Lord Kelvin for many suggestions and much valuable advice, both in regard to experiments and to the discussion of results; and to Professor J. J. Thomson for similar kindnesses during my work in the Cavendish Laboratory. A small portion of this investigation, on the effect of Röntgen $x$-rays on the contact electricity of metals, was published in the Proceedings of the Royal Society for March 1896.

I have also to thank Professor James Holm, M.A.*, and Mr. George E. Allan, B.Sc., for the part they took in the earlier portion of the work.

\section{Method of Experiment.}

\$3. The measurement of the natural potential-difference between any pair of conductors was usually made, in air, by the null method described very briefly by Lord Kelvin in the Report of the British Association for 1880, p. 494. To make clear the exact circumstances in which the potentials were measured it will be advantageous to describe the apparatus and general method of experiment in detail.

$\S 4$. A circular disk of one of the metals, usually about

* When this was written last August my friend and former fellowworker was Professor of Applied Mathenatics in the South-African College, Cape Town. He died in October. 
9 centim. in diameter and 2 centim. thickness, is insulated and in permanent connexion with the insulated pair of quadrants of an electrometer. A similar plate of the other metal placed parallel to the first, at a distance of a few millimetres from it, is uninsulated and in connexion with the uninsulated pair of quadrants. While in this position they are temporarily connected with one another through a simple form of potential-divider in which a slope of potential is maintained by a Daniell cell, in the direction opposite to that given by the experimental plates. The temporary connexion is now broken and the plates are separated. In doing so the capacity of the condenser is reduced, hence if there be any electric charge on them it will be indicated by a further deflexion of the electrometer. This operation is repeated with different values of the counterpotential until separation of the plates produces no change in the deflexion of the electrometer. Since it has annulled the charge, the counterpotential must now be equal and opposite to the natural potential-difference.

$\S 5$. During most of the experiments a piece of apparatus made by Lord Kelvin in or about 1861 was used. In it the plates were surrounded by a cylindrical zinc ease. This was made in two parts for convenience in manipulation, the lower fixed to a heary cast-iron base plate, while the upper stood upon small brackets attached to the top edge of the lower part, its position being regulated by a hole-slot-and-plane arrangement. Openings in the sides of the upper part facilitated the adjustment of the experimental plates, but these were closed by a sliding cuver during a measurement of potential.

The lower plate was supported by an insulating glass stem which was kept dry by means of pumice and sulphuric acid. On the top of this stem was a brass cap screwed to fit the sockets which were soldered to the backs of the plates, and from the brass cap a stiff' wire passed out througi a hole in the case and formed the comnexion between the insulated plate and the electrometer.

A piece of platinum foil was soldered round a part of this wire to give a clean contact for the temporary connexion between the plates through the potential-divider, and the wire from the divider had likewise a platinum end piece.

The upper plate hung, by a ring at the centre of its back, on a hook at the lower end of a vertical metal rod which could be drawn up so as to increase the distance between the plates. A small disk fixed on the rod at right angles to it just above the hook had three screws passed through it and pressed 
against the plate, holding it firmly in the hook; by this means the upper plate con be set parallel to the lower one in a very short time. This apparatus, which is the same as that used by Lord Kelvin in his experiments many years ago, was found to be very convenient, the arrangements enabling us to take out and replace a plate very rapidly, a matter of great importance when observing temporary variations, while at the same time both plates were firmly attached to their supports when in position.

$\$ 6$. The divider, whose total resistance was about 2400 ohms, was made to divide the potential-difference between its outer terminals into one hundred equal parts. The potential applied was usually that given by a Daniell cell of Tord Kelvin's gravity type, and was tested frequently by comparison with a standard Clark cell, or by means of a standard resistance and a current balance.

$\S 7$. The permanent connexions were as follows: $-(1)$ The lower plate to the insulated pair of quadrants of the electrometer ; $(2)$ The terminals of the Daniell cell to the ends of the divider (there wats a reversing plug in this circuit) ; (3) One end of the divider to the upper plate and uninsulated quadrants of the electrometer.

The temporary comnexion $(\$ 5)$ was from the sliding contact-piece of the divider to the lower plate.

$\S 8$. Each experiment was as a rule begun by polishing a metal plate on clean glass-paper or emery-cloth. Its contact potential with a standard plate, generally of electrolytically deposited gold washed some hours previously with alcohol, as used by M. Pellat, was then measured. The plate was next subjected to some particular treatment; for instance it was filed, or burnished, or polished on leather or paper, or washed with water, alcohol, or turpentine, or heated in air and oxidized, or not oxidized, or exposed to steam, or oxygen, or fumes of iodine or hydrogen sulphide, or simply left to alter under the influences of the atmosphere and its own molecular forces. Its potential with the same standard plate was again measured, and the change due to the treatment its surface had undergone noted.

$\S 9$. The metal which requires to be joined to the zinc end of the battery, in order to effect a balance, will be called positive. Thus aluminium is positive to zine and zinc positive to copper. Also, when a plate becomes more positive its potential will be sail to rise; when more negative, to fall. When the "potential" of a plate is mentioned, without other qualification, its contact potential-difference with a standard plate $(\$ 8)$ is meant. 
$\S 10$. The results given are not in the order in which they were obtained, but are classified in such a way as to show more clearly their true import, and those of many experiments which are not mentioned in the text will be found in the tables.

\section{Effects of different Metlods of Cleansing the Metallic Surfaces.}

$\S 11$. It seems probable that the very conflicting results obtained by different experimenters for the potential-difference of any given pair of metals, in air, must be due, to a large extent, to differences in the methods by which the surfaces have been prepared. In order to obtain a metallic surface as free as possible from all contamination it is clear that a hard polishing agent, such as a clean steel file, or emery-cloth, or glass-paper, must be used, as a softer material leaves more of itself on the plate. A liquid is quite unsuitable, since every particle of the metal probably retains particles of the liquid adhering to it. Thus the smèll of a liquid remains long after the plate appears to be quite dry; and it has been found that such a film as must exist to cause the odour is quite sufficient to alter the potential very considerably.

$\S 12$. In order to obtain uniformity of action the clean glass-paper or emery-cloth used to polish a plate was fixed on a wooden roller mide to revolve with a circumferential velocity of about 100 centim. per second. Care was taken to hold the plate so that the scratches, caused by the polisher, should all be parallel. Thus little or no grit could lodge in the surface, which would have occurred had the scratches crossed one another. A record was kept of the nature of the polishing agent in every case. A piece of glass-paper, or other polisher, was seldom used more than once or twice, and was never used for any different metal.

$\$ 13$. M. Pellat found that every change in the smoothness of a surfuce is accompanied by a change in its contact potential; but as his experiments were limited to metals washed with alcohol, it was of interest to extend them to more general cases. Thus a plate of zinc which had been polished on clean glass-paper, and had therefore a surface sharply scratched in parallel lines, was found to be

$$
.70 \text { rolt }
$$

positive to the standard gold plate. It was next burnished with a tool of hardened steel, and with the same standard plate it now gave 
Two hours later the same plate gare

$$
.92 \text { volt, }
$$

showing that the effect is nearly permanent. By burnishing the plate again a finer polish was obtained. With the same standard the potential is now

$$
1.00 \text { volt, }
$$

still further burnishing giving

$$
1 \cdot 02 \text { volt. }
$$

If the zine be now polished on glass-paper it returns to its original potential. Now steel, of which the burnisher was made, is negative to zinc; hence this rise cannot have been due to particles of steel on the zinc, but must have been caused by some change involved in the smoothing process to which the zinc had been subjected, possibly by a hardening of the surface layer.

$\$ 14$. Intermediate states of polish give intermediate values of potential. For instance, if a zinc plate be filed it will not be so sharply scratched as it would be by glass-paper, and of course not so smooth as if burnished. Its potential is also found to be between those of scratched and burnisbed zinc. Each polishing, with any given material, was usually sufticiently thorough to efface the effects of all previous polishings; the potential obserred thus depended only on the state of surface produced by the polisher used just before the observation. The results of experiments show that the smoother the surface the more positive it becomes.

$\$ 15$. The generalization given in $\$ 14$ is supported by the results of over one hundred similar experiments with a number of metals. The actual results are given in Table $I$. (pp. 406, 407); it will be well, however, to discuss some of these in greater detail than is possible in tabular form.

$\S 16$. In order to eliminate the use of different polishing agents, I tried the effect of producing different states of surface by rubbing the plate against another of the same metal. Two copper plates which had been polished on glasspaper gave

$$
\begin{aligned}
& \text { (a) }+.01 \text { volt, } \\
& \text { (b) }+.04 \text { volt, }
\end{aligned}
$$

with the standard plate. They were next gently rubbed together until parts of each were shiny, and now gave, with the same standard,

$$
\begin{aligned}
& \text { (a) }+.07 \text { volt, } \\
& \text { (b) }+.07 \text { volt. }
\end{aligned}
$$


In another experiment two coppers which had been polished

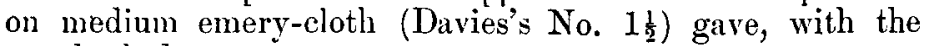
standard plate,

$$
\text { (a) }-.11 \mathrm{v} .
$$

When slightly burnished by rubbing them together, they gave

$$
\begin{aligned}
& \text { (a) }-.02 \mathrm{v} \\
& \text { (b) }-.02 \mathrm{v} .
\end{aligned}
$$

Thus, smoothing by mutual friction male hoth more positive. The amount of the change is not great, either in potential or in smoothness, as it is very difficult to polish copper on copper, but the direction of 'change is the same as previously found, namely, a smooth surface is more positive than a sharply scratched one.

$\$ 17$. On account of the difficulty of obtaining a burnished surface by simply rubbing two pieces of the same metal together, I tried another form of experiment in which the possible effect of the material of the polishing agent is eliminated by using the same tool to produce different states of surface. Thus a copper plate was scratched very ronghly with a steel tool, and gave

$$
-\cdot 07 \mathrm{v} \text {. }
$$

with the standard plate, then burnished slightly with the same tool it gave

$$
-.02 \mathrm{v} .
$$

It had thus risen $.05 \mathrm{v}$. on account of the alteration produced in smoothing its surface. Thus these results also confirm the conclusion given in $\$ 14$.

$\S 18$. It should be noticed that although individual results occasionally appear to conflict, the average value of the potential of any given metal when polished with a certain agent is almost always in proportion to the smoothness of the surface produced. However much one may try, it is impossible to get exactly the same state of surface over again, but by taking the average of a considerable number of experiments with one polishing agent, a general value is got which represents the potential given by the plate in a certain state of polish. It is so arranged that the sharply scratched surfaces come at the head of the table, and each succeeding polishing agent in the list produces a smoother surfuce.

$\S 19$. It should be observed that with soft metals such as tin, different polishers produce but little change in the contact potential. This, though at first sight apparently contrary to 


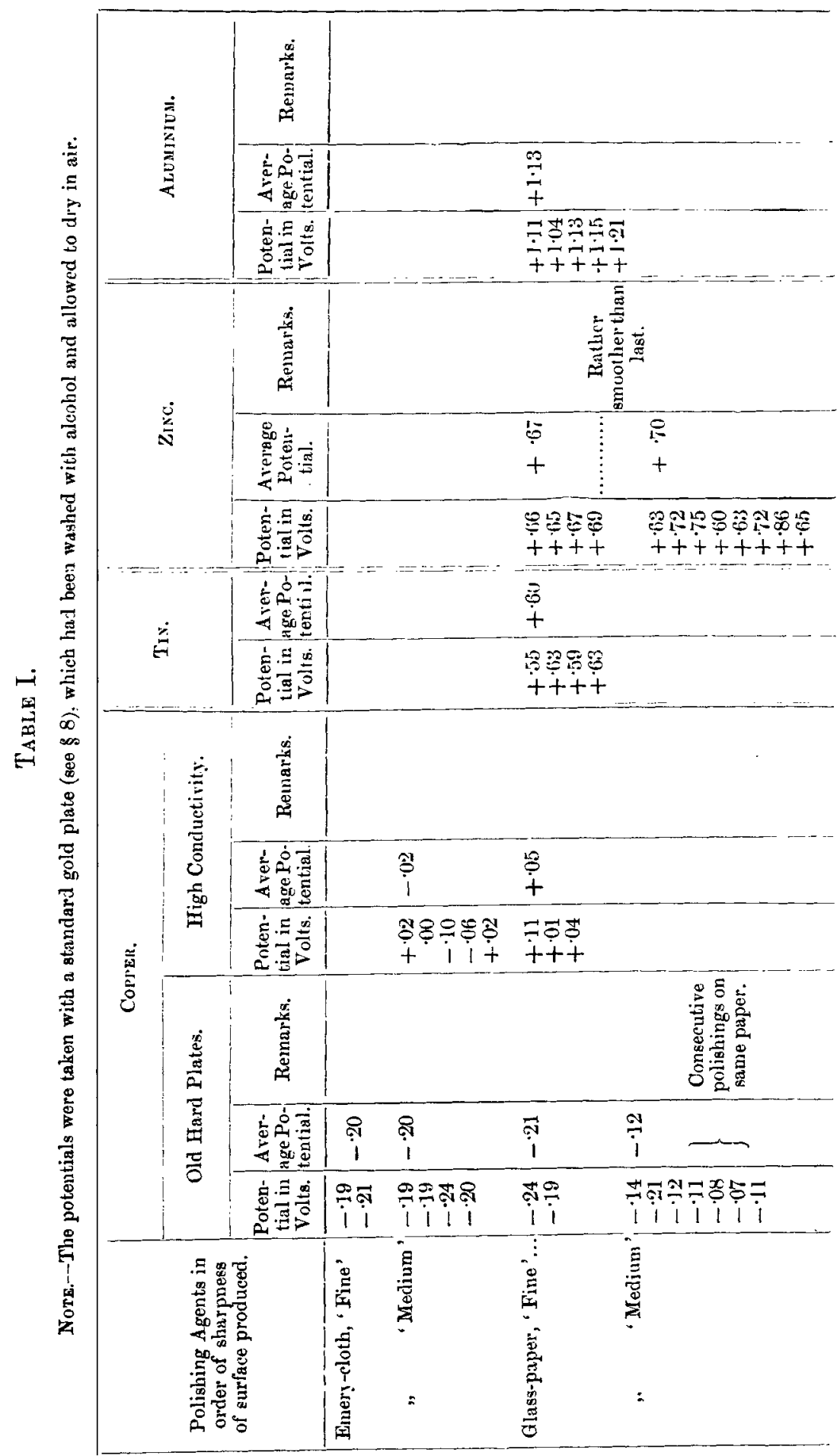




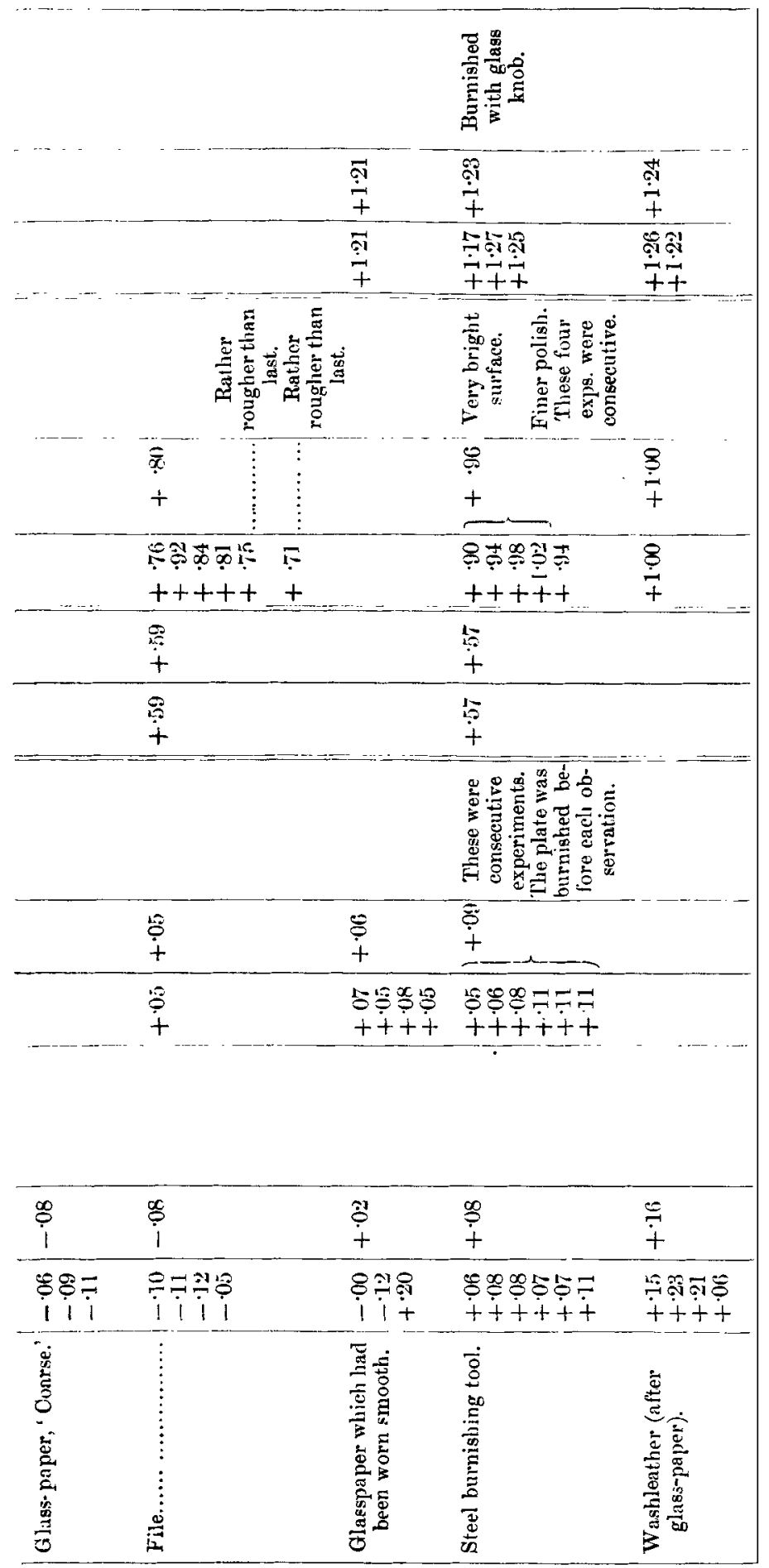


the results for harder netals, is really in accordance with them, for different polishers do not produce ipprecinbly different states of polish on a soft metal. This remark applies equally to the fuct that a smaller variation was observed with "high conductivity" copper than with the old copper plate, as the old p'ate was found to be considerably harder than the purer "high conductivity" copper.

$\S 20$. It is probable that the variation described in this chapter is not directiy due to roughness or smoothness, but rather to alteration, either by change in the outer layer of the metal, or in the film of condensed air which no doubt exists on it, of the interface between metal and air.

\section{Thin Solid Films of Oxides, Iodides, \&c.}

$\S 21$. Among the earlier experiments were many in which the changes due to films of oxide of different thicknesses were studied ; indeed this was the primary object of investigation suggested by Lord Kelvin. But constant difficulties and ambiguities presented themselves, hindering the interpretation of even the simplest experiments, and it was found necessary to enlarge the scope of the research in order to remove or explain them.

$\S 22$. The experiments detailed below are among the most definite of those carried out. They show large changes in potential on account of very thin films of oxide, and prove that the amount oî change is dependent on the thickness of the film when below a certain limit.

$\$ 23$. Two plates of cast zinc, which had been carefully polished on medium glass-paper the day before, gare with one another

$$
+\cdot(0) 2 \mathrm{v},
$$

the upper plate being positive. The upper plate was now taken out and heated on the back by means of a very small blowpipo flime. Its face became slightly blistered, but not much discoloured, and when cold it gave with the other, which had not been altered in any way,

$$
-44 \mathrm{v} .
$$

the "minus" indieating that the upper is now negative. This shows a permanent fall of 46 v. due to heating in air.

$\S 24$. A plate of rolled zinc, which gave $-.04 \mathrm{v}$.

with another plate of the same material, was heated as in the last experiment but to a higher temperature, very nearly to its melting-point. Its face became a streaky yellowish brown, 
slightly purple towards the centre (the brown parts turn purple if moistened). When cold, compared with the clean plate it now gave

$$
-.79 \mathrm{v} \text {, }
$$

a fall of $\cdot 75 \mathrm{v}$. Thus this oxidized zine plate has practically the same potential as copper. This great fall of potential does not take place by exposure to the atmosphere at ordinary temperatures, unless possibly after the lapse of many years, for the potential of zinc plates which have been left unpolished for many months is only two or three tenths of a volt below that of clean zinc (see $\$ 34$ ).

\$25. Similar experiments were made with copper. The film of oxide was gradually increased in thickness by repeatedly heating the plate, and the potential measured in each stage of oxidation, the plate being cold. There was a change of about $03 \mathrm{v}$. in the negative direction before the oxide-film became visible, and further increase in the thickness of the film was judged by the gradual change of colour, until the well-known dull purplish black of massive copper oxide was attained. The potential, measured each time when the plate was cold, gradually fell until it reached a limit of about -30 volt negative to a standard gold plate, which value may therefore be taken as the potential of a mass of copper oxide at $15^{\circ} \mathrm{C}$. It may be remarked that there are good reasons, which will be given in Chap. IX., for supposing that oxidation does not commence in air unless the temperature of the plate be raised above $80^{\circ} \mathrm{C}$.

$\$ 26$. A plate of copper which had been polished on glasspaper and then on wash-leather gave

$$
+\cdot 20 \mathrm{v} \text {. }
$$

with a standard gold plate, and was next held in iodine vapour for a short time. It looked moist at first, but quickly became dry. In this state it gave $-\cdot 34 \mathrm{v}$.

with the same standard, a change of $54 \mathrm{v}$. in the negative direction. The surfice had a dull colour with a whitish "bloom" on it, the tint resembling that of clean copper, though rather darker. Exposure to iodine rapour thus makes the surface of copper nearly as negative as continued exposure to the atmosphere at a high temperature.

$\$ 27$. The potential of a clean zinc plate fell about $\cdot 12 \mathrm{r}$. when it had been exposed to iodine vapour.

$\$ 28$. The iodine compounds formed on tha metallic surfaces were not stable, as the appearance and potential of the plates altered considerably during twenty hour.' exposure to the atmosphere. 
$\S 29$. The effects of sulphur-fumes, hydrogen sulphide, \&c., were tried, but, though in most cases considerable changes were observed, the results obtained were not satisfactory.

\section{Atmospheric or Time Effects.}

$\S 30$. A small variation of the potential is usually found to take place during a short time after the plate has been polished, and before it has settled down to a more or less permanent value. This is partly due to the fact that the plate has been slightly warmed during polishing, and takes some time to come to the atmospheric temperature (see Chap. 1X.). As regards changes which are not due to variation of temperature, I shall give some typical experiments in the following sections of this chapter.

\$31. Two plates of "high conductivity" copper were polished on fine glass-paper, and several experiments by burnishing them by mutual friction were then made (see $\S 16)$. Forty-seven minutes after the original polishing their potentials with the stindard plate were

$$
\begin{aligned}
& \text { (a) }+.035 \mathrm{v} . \\
& \text { (b) }+.045 \mathrm{v} .
\end{aligned}
$$

The plate $(a)$ was left in the apparatus all night, that is 10 say, in a position sheltered from dust, and in air partially dried by the sulphuric acid in the lower part of the case ; the potential next morning, $20^{\mathrm{h}} 3^{\mathrm{m}}$ after the measurements given above, was

$$
+\cdot 045 \mathrm{v} \text {. }
$$

with the same standard plate. It was thus nearly constant. The plate $(b)$ was left in a rack in the lahoratory without special protection, with the result that next morning the potential, owing to exposure to the air of the room for about $20^{\mathrm{h}}$, had fallen to

$$
-.056 \mathrm{v} \text {, }
$$

a change of $-101 \mathrm{v}$. The plate $(b)$ was now placed in the apparatus, and remained nearly constant for two hours at least. Plate $(a)$ was left in the rack, :nd its potential fell $.065 \mathrm{v}$. in about 2 hours. It is thus evident that at ordinary temperatures in a rather dry atmosphere, and in a place protected from dust and light, the rate of variation of the contact-potential of copper is very small; in an exposed place, however, it is by no means negligible.

$\S 32$. A plate of block tin was polished on glass-paper. Its potential varied with time as follows, the time being counted from the completion of the polishing :- 
Volta Electrinity of Metals.

\begin{tabular}{|c|c|c|c|}
\hline His. & Min. & & Volts. \\
\hline 0 & 22 & . & +.515 \\
\hline 0 & 27 & . & $+\cdot 520$ \\
\hline 0 & 46 & & $+\cdot 535$ \\
\hline 1 & 4 & . & +.535 \\
\hline 1 & 23 & & +515 \\
\hline 3 & 18 & & . +-495 \\
\hline 4 & 6 & & . +.495 \\
\hline 4 & 42 & & +.495 \\
\hline 71 & 12 & & $+\quad+465$ \\
\hline
\end{tabular}

The plate was kept in the apparatus all the time and its potential taken with a standard gold plate.

$\S 33$. In another experiment a tin plate polished on the finest glass-paper gave, after $0^{\mathrm{h}} 15^{\mathrm{m}}$,

\section{After $23^{\mathrm{h}} 30^{\mathrm{m}}$ it gave}

$$
+\cdot 525 \mathrm{v} \text {. }
$$$$
+\cdot 535 \mathrm{v} \text {. }
$$

This experiment was made in June, while the previous one was made in December. Hence probably the greater rate of variation in the former was due to a moister and less pure atmosphere.

\$34. An old zinc plate which had probably not been polished for many years gave

$$
+\cdot 37 \mathrm{v} \text {. }
$$

with the standard gold plate. It was next polished on glasspaper, and gave

$$
+\cdot 75 \mathrm{v} \text {. }
$$

with the same standard. This shows that the ultimate effect of exposure is to make the potential of zinc fall. I have found that in some cases this fall is preceded by a slight rise, as in the case of tin $(\$ \S 32,33)$; but the ultimate effect is in the negative direction.

$\$ 35$. The potential of a silver plate which had been polished on glass-paper remained constant for an hour. The experiment was not continued further.

$\S 36$. Aluminium becomes gradually negative in air. In one case the potential fell about $\cdot 18$ v. in a week. The time-change of this metal, mainly on account of its large temperature-rariation (see Chap. IX.), is rather difficult to determine.

§37. An iron plate which had not been cleansed for two months rose $.05 \mathrm{v}$. when polished. Hence the effect of exposure had been to make its potential fall slightly.

\$38. I have included these results, for which, as for many others like them, I can as yet give no definite explanation, 
in the hopo that they may serve as a basis for future experiment and generalization. The great difficulty in all such experiments on contact electricity is to define the circumstances and, with them, the causes of any given variation.

\section{Very Thin Liquid Filins on Metals.}

$\$ 39$. In the earlier experiments it was found that, as a rule, copper polished on glass-paper or emery-cloth was about .20 v. negative to the standard alcohol-washed gold plate. On comparing this value with M. Pellat's results* I found that his value for copper was about $\cdot 20$ positive to the same standard. I at once determined to try his method of cleansing the plate so as to find if the difference ( 40 volt) were due to that alone. For this purpose a copper plate was carefully polished on glass-paper. It gave, with the standard,

$$
-\cdot 20 \mathrm{v} \text {. }
$$

It was then washed with alcohol and allowed to dry in air. It now gave

$$
+\cdot 22 \mathrm{v} \text {. }
$$

with the same standard. The change due to the treatment is therefore $+\cdot 42$ volt, and continues permanent many hours.

$\S 40$. A plate of thickly oxiclized copper giving, with the standard plate, $-24 \mathrm{v}$.

gave, after it had been washed with alcohol and allowed to dry,

$$
.00 \mathrm{r} \text {. }
$$

a rise of $\cdot 24$ volt.

$\S 41$. A zinc plate, when cleaned on glass-paper, gave

$$
+\cdot 61 \mathrm{v} \text {. }
$$

It was then washed with alcohol, and when apparently quite dry gave

$$
+\cdot 94 \mathrm{v} .
$$

remaining constant at this value for many hours. The rise in this case is $\cdot 33$ volt.

$\S 42$. The resuits of many similar experiments made with alcohol and other liquids on gold, silver, zine, copper, iron, tin, lead, and aluminium will be found in Table II. It is notable that in almost every case the contact-potential of a metal which has been polished on a lard dry material rises at least $\cdot 15$ volt in consequence of alcohol washing, and that this change is nearly permanent for many hours after the plate appears to be quite dry.

$\S 43$. It may be remarked that, as $M$. Pellat appears to have invariably washed the metal with alcohol before making a measurement of its potential, his results do not apply

* Avn. de Chimie et de Physique, 1881. 
directly to metals which have been cleaned by means of a hard dry agent only. Eren in the experiment which he gives on pp. 79-80 of his paper as a proof that alcohol-washing does not permanently alter the potential of a clean gold plate, he appears to have used a plate which had already been washed with alcohol ; his result, therefore, does not prove that alcohol-washing makes no change in contact-potential of a clean plate, but only that subsequent wasbings do not alter the state of surface, $i$.e that the effect is nearly permanent. This agrees with the results given above and in Table II.

$\S 44$. The alcohol film, whether in combination with the metal or not, must in any case displace the air from the surface of the plate. Other liquids secm to leave films in much the same way, though the change of potential is different for each liquid; in some cases, e.g. turpentine on zinc and copper, it is in the positive direction for the positive metal and in the negative for the other.

TABLE II.- Permanent Changes produced in (ontact-potential of Metals by washing with Alcohol and drying in Air.

\begin{tabular}{|c|c|c|c|c|}
\hline \multirow{2}{*}{ Metal. } & \multirow{2}{*}{ Previous treatment. } & \multicolumn{3}{|c|}{$\begin{array}{l}\text { Potential with standard } \\
\text { gold plate. }\end{array}$} \\
\hline & & Before. & After. & Change. \\
\hline Copper & Polished on glass-paper ............... & $\begin{array}{l}\text { volt. } \\
-\cdot 20\end{array}$ & $\begin{array}{l}\text { volt. } \\
+22\end{array}$ & $\begin{array}{r}\text { volt. } \\
+42\end{array}$ \\
\hline$"$ & Polished on emery-cloth ... & $\begin{array}{l}+09 \\
+02\end{array}$ & $\begin{array}{l}+29 \\
+\cdot 14\end{array}$ & $\begin{array}{l}+20 \\
+\cdot 12\end{array}$ \\
\hline & 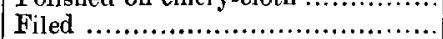 & $\pm \cdot 13$ & $\begin{array}{l}+19 \\
+\cdot 14\end{array}$ & $\begin{array}{l}+12 \\
+.27\end{array}$ \\
\hline & Oxidized............................. & -24 & 00 & $+\cdot 24$ \\
\hline Gold ......... & Polished with dry "plate-powder" & ....... & ...... & $+0 \tilde{5}$ \\
\hline Silver ......... & Polished on glass-paper & +10 & $+\cdot 20$ & $+\cdot 10$ \\
\hline Iron $\ldots . . . .$. & Dry-polished ...................... & $+\cdot 08$ & $+\cdot 16$ & +08 \\
\hline$" \quad \ldots \ldots \ldots$ & Polished on emery cloth .................. & $+\cdot 17$ & $+\cdot 29$ & +12 \\
\hline$" \quad \cdots \cdots \cdot . . .$. & (.................. & ….. & ...... & $\begin{array}{l}+17 \\
+.14\end{array}$ \\
\hline$" \cdots$ & n................ & ….. & $\cdots \cdots$ & $+\cdot 14$ \\
\hline Lead & Scraped thoroughly with a knife $\ldots$ & $+\cdot 61$ & +80 & $+\cdot 19$ \\
\hline $\operatorname{Tin} . . . .$. & Polished on glass-paper ............... & $+\cdot 56$ & +66 & $+\cdot 10$ \\
\hline Zine ... & Polished on glass-paper ................ & $+\cdot 61$ & +994 & $+\cdot 33$ \\
\hline Aluminium & Polished on glass-paper ............... & $+1 \cdot 05$ & $+1 \cdot 10$ & $+\cdot 05$ \\
\hline$"$ & $" \quad$, $\quad \ldots \ldots \ldots \ldots$ & +1.04 & $\begin{array}{l}+1.07 \\
+1.08\end{array}$ & +03 \\
\hline$"$ & $" \quad " \quad$ " $\quad$ " $\quad$ ".................... & $+1 \cdot 17$ & $\begin{array}{l}+120 \\
+1.26\end{array}$ & +09 \\
\hline & & & & \\
\hline
\end{tabular}

Phil. Mag. S. 5. Vol. 45. No. 276. May 1898. 


\section{Thick Liquid Films on Metals.}

$\$ 45$. In experimenting with films of sensible thickness the liquid was usually placed on a flat metal plate, its surfacetension being sufficient to retain it if its depth were not more than $\cdot 3$ or $\cdot 4$ centim. In other cases a shallow metal dish was used. The behaviour of water puzzled me for some time, and made me realize the extreme difficulty of obtaining a clean liquid surface. After some preliminary experiments I found that distilled water which has not been exposed to the atmosphere gives fairly constant results when lying to a depth of $\cdot 2$ centim. on one of the standard gold plates. When water on gold formed the one plate and a dry standard gold plate (see 8 ) the other, the value found was 10 volt, the water being negative. Thus clean water in contact with gold is about $\cdot 10$ volt negative to it. The value found is quite different if the water has been exposed to the air for some time, and is usually positive instead of negative to the standard plate.

$\S 46$. Air expelled from the lungs produces a very marked change in the contact-potential of water. By blowing through a fine glass tube which dipped under the surface of a layer of distilled water on a gold plate, the potential was changed from $-\cdot 10$ v.

with the standard plate to

$$
+\cdot 16 \mathrm{v} . \text {, }
$$

and remained at this latter value for more than half an hour, showing that the change was not due to a rise in temperature. The curious point is that the change seems to be only in the surface of the liquid; for when most of it was shaken off the potential fell to

$$
-\cdot 05 \mathrm{v} .
$$

although the plate was still wet all over. This appears as if the alteration were due to a surface film of oily or dusty matter on the witer. It was found that distilled water which had been exposed to the air of the room for some time gave the same value as water which had been breathed through.

$\S 47$. A lead plate and a flat circular leaden dish were scraped clean with a knife, and next morning, when compared with each other, they gave

$$
+\cdot 10 \mathrm{v} \text {, }
$$

the plate being positive to the dish. Water was now poured into the dish until it was nearly full, $\cdot 4$ centim. deep, the 
potential remaining the same; $i$. e. the lead plate gave with the water in the leaden dish,

$$
+\cdot 10 \mathrm{v} \text {., }
$$

water in leaden dish being negative.

$\$ 48$. The plate and dish were again seraped, and this time they gave

$$
+.05 \mathrm{v} \text {., }
$$

the plate being positive. Water was next poured into the dish, which gave, with the dry lead plate,

$$
+.09 \mathrm{v} \text {., }
$$

the water in the dish being negative as before. The dish was now removed and a standird gold plate put in its place; with this the lead plate gave

$$
+.52 \text { v., }
$$

the lead being positive. Thus water in contact with lead is about $\cdot 09 \mathrm{v}$. negative to dry lead.

$\$ 49$. Turpentine seems to produce opposite effects on zine and copper, $i$. $e$. copper becomes more negative and zinc more positive when wet. Thus copper and zinc which had been dry-polished gave with one another

zinc positive.

$\cdot 77 \mathrm{v}$,

With the zine wet with turpentine,

$\cdot 96 \mathrm{v}$.

And with both zine and copper wet about

$$
1 \cdot 20 \mathrm{v} \text {. }
$$

Their potential-difference increased somewhat as the turpentine dried up; and when apparently quite dry its value was still at least

$$
1 \cdot 20 \text { v., }
$$

the plates, however, smelt strongly of turpentine, showing that an invisible layer remained on their surfaces.

$\$ 50$. A crystal of copper sulphate gave, with a standard gold plate,

$$
\text { +.02 v., }
$$

copper sulphate positive. This result was obtained in connexion with some experiments on the contact-potential of an aqueous solution of copper sulphate. It was found that such a solution in a copper dish gave about +.07 volt with a dry standard gold plate, the solution being positive. Blotting$2 \mathrm{~F} 2$ 
paper saturated with copper sulphate gave about $+\cdot 10$ volt with the same standard plate. As no special precautions were taken in these experiments to obtain a perfectly pure liquid surface, one cannot, especially in view of the changes described in $\$ 46$, be quite certain that they represent the true potential of copper conted with a solution of its sulphate. They agree, however, with Professors Ayrton and Perry's values for saturated and non-saturated solutions.

$\$ 51$. One of the standard gold plates which had been polished with Hollis's plate-powder used dry gave, with a similar plate which had a layer of alcohol on it,

$$
-13 r \text {. }
$$

When the alcohol had dried up the value was

$$
-.05 \mathrm{v} \text {., }
$$

the polished plate being negative as before.

$\$ 52$. The conclusion which I draw from the experiments described in this and the preceding chapter and in the tables is, that a layer of liquid on a metallic surface does not give, with a metal separated from it by air, a definite potential-difference of its own, as in similar circumstances a solid conducting film would do, but merely adds a certain amount to that of the plate on which it lies. Thus two different metals coated with layers of the same liquid do not, as a rule in air, give zero potential-difference, but usually give nearly the same potentialdifference as the dry metals. For instance, the potential of lead with an alcohol layer 1 centim. deep on it is about $\cdot 13$ volt higher than that of dry lead, while that of wet copper is about the same amount higher than the average value for dry copper. There is no tendency shown for a liquid film to take up a definite potential independent of that of the metal on which it lies, with any metal separated from it by a dielectric, as a solid conducting film would do. This seems to be the most important distinction between solid and liquid conductors, and it is in accord with what is known of voltaic cells; for if the potential-differences in the chain copperwater-zinc were equal and opposite to that of zinc-copper, as copper-iron-zine is to zinc-copper, we should have no electromotive force in the circuit, when the materials are all at one temperature. In most of my experiments the type is copperwater-nonconductor (air)-water-zine and not copper-waterzinc; the members of the first and last pairs are in contact, while a non-conductor intervenes between the two free water surfaces, these being able to take up their natural contactpotential-differences with the metals they touch; but the sum 
of the potentials, copper-water and water-zine, is not equal to copper-zine, thus proving that the two free surfaces of water are not at the same potential. This is directly demonstrated by the experiments of Professors Ayrton and Perry, and by the results given in Chaps. VI., VII., and X. of this communication.

If the intervening layers of non-conductor be removed by joining the liquid surfaces so that there is but one mass of liquid between the plates, conduction at once tends to reduce the whole liquid to the same potential, leaving the contactpotential-differences, now unbalanced by the remoral of the non-conducting medium which was capable of sustaining the stress, to act as external electromotive force. This then shows the connexion between contact-potentials, measured electrostatically by the method described in this paper, and the electromotive force of a voltaic cell.

\$53. The contact-potential of a liquid with a metal is clearly, if the air-potentials be neglected, the difference between the potential of the dry metal and that of the metal when wet with the liquid; the same standard plate being ased as zero of potential in both cases. The results given in the tables must no doubt be in some cases complieated by the formation of solid compounds in the interface between liquid and metal so that the liquid is no longer in contact with clean metal, and the liquid must also displace any film of condensed air which may exist on the metal. The latter influence will be discussed in Chaps. VIII. and X.

TABLE III.-Potential of Metals covered with visible layer of Alcohol.

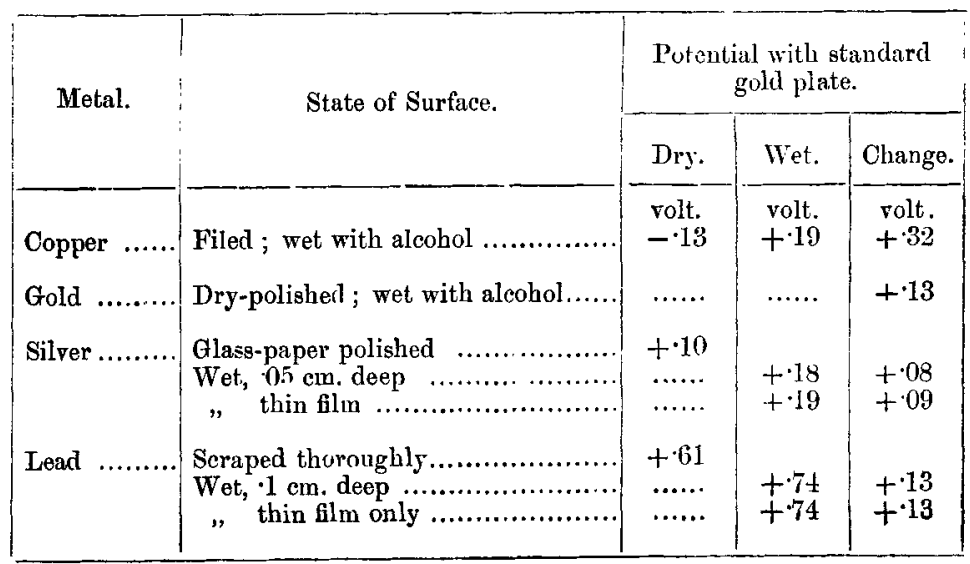


Table IV.-Change in Contact-Potential of Zine and Copper due to Layers of Turpentine, Rosin Oil, and Indiarubber Solution.

\begin{tabular}{|c|c|c|c|c|}
\hline \multirow{2}{*}{ Iiquid. } & \multirow{2}{*}{ Motal. } & \multicolumn{2}{|c|}{ Potential, volts. } & \multirow{2}{*}{ Remarks. } \\
\hline & & & Change. & \\
\hline Wet with turpenine. & $\begin{array}{l}\text { Copper, polished on } \\
\text { glass-paper. } \\
\text { Zinc, pnlished on glass- } \\
\text { paper. }\end{array}$ & $\cdots \cdots$ & $\begin{array}{l}-\cdot 11 \\
+\cdot 20\end{array}$ & $\begin{array}{c}\text { Note. -The plates were } \\
\text { compared with one } \\
\text { anotber, and not with } \\
\text { the standard plate. } \\
\text { Hence onl thechange }\end{array}$ \\
\hline Wet with rosin-oil ... & $\begin{array}{l}\text { Copper, polished on } \\
\text { glass-paper. } \\
\text { Zinc, polished on glass- } \\
\text { paper. }\end{array}$ & …. & $\begin{array}{l}-\cdot 12 \\
-\cdot 02\end{array}$ & of potential is given. \\
\hline $\begin{array}{l}\text { Wet with india rubber } \\
\text { oolution. }\end{array}$ & $\begin{array}{l}\text { Copper, polished on } \\
\text { glass-paper. } \\
\text { Zinc, polished on glass- } \\
\text { paper. }\end{array}$ & $\ldots$ & $\begin{array}{r}+.02 \\
+.07\end{array}$ & \\
\hline
\end{tabular}

VIII. Films formed on Metals by Gases.

$\S 54$. The potential of a metal is usually altered by soaking the plate in a gas other than air. If the gas be oxygen, this alteration is as a rule only temporary, and apparently depends on the formation of a surface film, or rather on a change in the film which doubtless already exists. It will be shown that the change of potential of zinc due to soaking in oxygen is nearly equal to that of copper ; hence the film of oxygen acts like a liquid film (Chap. VII.), but its effect is less permanent. Previous experimenters, except Lord Kelvin, appear to have neglected the existence of these films, and to have looked only to the nature of the body of gas between the plates. Of course I do not here allude to the "doublelayer" which has been offered as an explanation of the phenomenon, but to a layer in mechanical and electrical contact with the metal. If the contact-potential of two metals immersed in a gas were the sum of the potentialdifferences between each metal and a skin of gas close to it, we should have no slope of potential in the body of the gas between the plates. 'That a slope does exist, however, is proved by Lord Kelvin's earliest experiments with the divided ring of copper and zinc. In this connexion Dr. Bottomley's research on contact-electricity in high vacua ${ }^{*}$ is of great importance as showing that the volta-potential of metals is

* B. A. Report, 1885 . 
not sensibly different in different gases so long as the metals are not chemically affected, and is not sensihly altered by a great reduction of pressure. The body of the gas may possibly have some influence, but the variations which have frequently been attributed to it may usually be more satisfactorily explained as being due to change in the film in contact with the metallic surface. In the case of a gas which acts vigorously on the metal at ordinary temperatures the film is permanent, and is probably a solid compound; in other cases it is not permanent, and hence probably not solid.

$\$ 55$. In "Nature" for 1881, Lord Kelvin describes some very important experiments on this subject. As these appear to be but little known I shall give some extracts from his paper before describing my own results. Under the date November 23, 1880, Lord Kंelvin says :- "I have found that a dry platinum disk, kept for some time in dry hydrogen gas, and tinen put into its position in dry atmospheric air in the Volta-condenser, becomes positive to another platinum disk which had not been so treated, but had simply been left undisturbed in the apparatus. The positive quality thus produced by the hydrogen diminishes gradually, and becomes insensible after two or three days. P.S.-On December 24, 1880 , one of the platinum plates in the Volta-condenser was taken out; placed in dried oxygen gas for forty-five minutes; taken out, carried by hand, and replaced in the Volta-condenser at 12.30 on that day. It was then found to be negative to the platinum plate, which had been left undisturbed. The amount of the difference was about 33 of a volt. The plates were left undisturbed for seventeen minutes in the condenser, and were tested again, and the difference was found to have fallen to 29 of a volt. At noon on the 25th they were again tested, and the difference found to be -18. The difference had been tested from time to time since that day, the plates having been left in the condenser undisturbed in the intervals. The following table shows the whole series of these results :- Electric difference between surfaces of a plativum plate in natural condition, and a platinum plate after

Time. 45 minutes' exposure to dry oxygen gas.

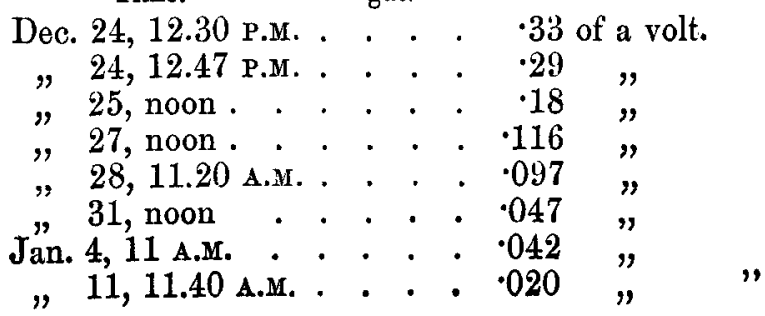


After detailing some experiments in which the plates were coated with the gases by electrolysis, Lord Kelvin concludes : "Thus in the case of polarization by oxygen, as well as in the case of polarization by hydrogen, the effect of exposure to the dry gas was considerably greater than the effect of electroplating the platinum with the gas by the electromotive force of one volt."

The large effects on contact-potential produced by films formed from gases are clearly shown in these experiments of Lord Kelvin's. It is well known that platinum and other metals have the property of occluding large quantities of gas in their surface layers, and that the condensed gas is possibly in the liquid state, which would account for the similarity between the effects of liquids and of gases on metals.

$\$ 56$. The plates with which my first experiments on this subject were made were of "high conductivity" copper. They had been polished on fine glass-paper five hours before, and their mutual potential had remained constant at

\section{.02 volt}

for four hours. The lower plate was then put into a glass vessel, into which oxygen gas was admitted from a cylinder, and the oxygen, which was of Messrs. Brin's manufacture, guaranteed 93-95 per cent. oxygen (nitrogen is usually the only impurity), was allowed to stream through the glass vessel containing the plate for some minutes, and the exit and inlet of the vessel were then closed. Forty-five minutes later the plate was taken out and its potential again measured with the other plate, which had remained in air during the interval. Counting time from the moment at which the plate was taken out of the oxygen, the potential varied as shown below, the oxygenized plate being positive to the other in all cases :-

\begin{tabular}{ccc}
\multicolumn{2}{c}{ Time. } & Contact-potential. \\
h. & m. & v. \\
0 & 3 & $\cdot 12$ \\
0 & 19 & $\cdot 08$ \\
0 & 30 & $\cdot 06$ \\
17 & 20 & $\cdot 03$
\end{tabular}

Thus the effect of increasing the proportion of oxygen in the surface film was to make the copper more positive.

$\$ 57$. This variation is in the opposite direction to that found by Lord Kelvin for platinum which has been soaked in oxygen. In order to make sure that this difference was not the effect of some impurity in the oxygen, I repeated his 
experiment, obtaining the same result as he had obtained. This shows that the result given above was not likely to be due to an impurity which had influenced the action of the oxygen.

\$58. Without any further treatment the same copper plate was placed in the bell-jar and the oxygen admitted. After forty-five minutes it was taken out and its potential again measured by comparison with the other plate. The results are given in the following table, time being counted from the moment the plate was taken out of the oxygen :-

\begin{tabular}{ccc}
\multicolumn{2}{c}{ Time. } & Contact-putential. \\
h. & m. & . \\
0 & 2 & $\cdot 13$ \\
0 & 10 & $\cdot 08$ \\
0 & 21 & $\cdot 07$ \\
0 & 29 & $\cdot 06$
\end{tabular}

The experiment was discontinued before the plate had returned to its original value; but it would no doubt have done so in a few hours, for the amount of change, and its rate, are almost exactly the same as in the former experiment (see $\$ 56$ ).

$\$ 59$. In the following experiment the conditions were somewhat varied. A copper plate was polished on glasspaper. It gave, with a standard copper plate,

$$
-.05 \mathrm{v} \text {. }
$$

A jet of oxygen was now sent against its surfice for two or three minutes, and with the same standard plate it now gave

$$
-.06 \mathrm{v} \text {. }
$$

It was then left in oxygen for twenty-five minutes, and on

\begin{tabular}{|c|c|}
\hline $\begin{array}{l}\text { Time. } \\
\text { h. } \quad \text { m. } \\
0\end{array}$ & $\begin{array}{c}\text { Contact-potential. } \\
\text { v. } \\
+\cdot 060\end{array}$ \\
\hline 13 & +035 \\
\hline
\end{tabular}
being taken out gave

which shows that its immersion had raised its potential $\cdot 12 \mathrm{v}$ I now warmed it with a soldering-bolt applied to its back. When about $47^{\circ} \mathrm{C}$. (see Chap. IX.) it gave

Time.

h. $\mathrm{m}$.

$0 \quad 16$
Contact-potential. v. $+\cdot 020$. 
It was again warmed slightly, and when at about $30^{\circ} \mathrm{C}$. gave

When $16^{\circ} \mathrm{C}$,

\begin{tabular}{lcl}
\multicolumn{2}{c}{ Time. } & Contact-potential. \\
h. & m. & v. \\
0 & 42 & $-\cdot 010$.
\end{tabular}

its potential thus coming back to very nearly the original value.

This experiment shows: (1) that the change requires considerable time; for even a fairly strong jet of oxygen playing on the plate for two or three minutes produces no appreciable effect, while twenty-five minutes in still oxygen causes a rise of $\cdot 20 \mathrm{v}$.: (2) that gentle heating does not produce a rise, as it would do with clean unoxygenized copper (see Chap. IX.), but it must be remembered that the copper was, when heated, already above the potential to which heat alone would have raised it; hence this experiment does not show any connexion between temperature-variation and density of the oxygen film as might at first sight be supposed.

$\$ 60$. A zinc plate which had been polished on glass-paper gave with a standard copper plate

$$
.81 \text { v., zinc positive. }
$$

It was then put into oxygen and left for fifteen minutes. After being taken out, its potential was again measured with the same standard plate, and was as follows .-

\begin{tabular}{ccc}
\multicolumn{2}{c}{ Time. } & Contact-potential. \\
h. & m. & V. \\
0 & 2 & .89 \\
0 & 10 & $\cdot 87$ \\
4 & 18 & $\cdot 86$ \\
4 & 35 & $\cdot 85$
\end{tabular}

This shows that zinc also is more positive atter immersion in oxygen.

$\$ 61$. The same zinc plate was again polished on glasspaper and gave

$$
+\cdot 73 \mathrm{v} \text {. }
$$

with the standard copper. A short time later it gave

$$
+\cdot 70 \mathrm{v} \text {. }
$$

It was now put into oxygen for ten minutes, and after being taken out gave

\begin{tabular}{rrc}
\multicolumn{2}{c}{ Time. } & Contact-potential. \\
h. & $\mathrm{m}$. & $\nabla$. \\
0 & 3 & $+\cdot 80$ \\
0 & 13 & $+\cdot 78$ \\
17 & 1 & $+\cdot 74$
\end{tabular}


Volta Electricity of Metals.

$\S 62$. A tin plate was polished on clean glass-paper, and gave with a copper plate

$$
+\cdot 40 \mathrm{v} .
$$

tin being positive. Fifteen minutes later the potential of the plates had not altered. I now put the tin into the bell-jar and turned on the oxygen. After it had soaked for 47 minutes it was taken out and compared with the same copper plate. It gave

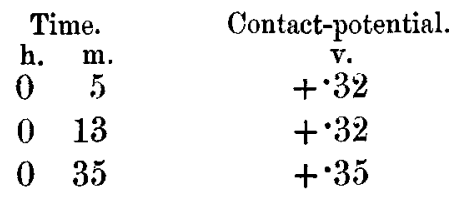

Thus the variation of tin appears to be in the negative direction, like that of platinum.

$\$ 63$. A silver plate, polished on glass-paper, gave with a standard copper plate

$$
-.04 \mathrm{v} .,
$$

and remained constant during an hour. It was then put into oxygen for 15 minutes, and when taken out its potential was

\begin{tabular}{|c|c|}
\hline $\begin{array}{l}\text { Tine. } \\
\text { h. } \\
0 \\
0\end{array}$ & $\begin{array}{c}\text { Contact-potential. } \\
\text { v. } \\
+.02\end{array}$ \\
\hline $\begin{array}{ll}0 & 19\end{array}$ & -.01 \\
\hline 40 & -.02 \\
\hline 45 & -.02 \\
\hline $\begin{array}{ll}0 & 59\end{array}$ & $-\cdot 03$ \\
\hline
\end{tabular}
found to be

Thus by immersion in oxygen for 15 minutes it had risen $.06 \mathrm{v}$., and had fallen to nearly its original value in an hour in air.

$\$ 64$. Silver polished on clean "fine" glass-paper gave with a standard copper

$$
-.095 \mathrm{v} \text {. }
$$

After it had been 24 minutes in oxygen it gave in air

and 12 minutes later

$$
+\cdot 015 \mathrm{v} \text {., }
$$

$$
+\cdot 010 \mathrm{v} \text {, }
$$

showing that the potential had in 24 minutes in oxygen become $\cdot 110$ more positive.

$\S 65$. It is noticeable that the amount of change in these experiments on silver is to some extent proportionate to the 
time of exposure to oxygen. Thus, in $\S 63,15$ minutes in oxygen caused a rise of $\cdot 06 \mathrm{v}$.; while, in $\$ 64,24$ minutes in oxygen caused a rise of $\cdot 11 \mathrm{v}$., but there is no doubt a limit to the change.

$\$ 66$. In searching for an explanation of the temperaturevariations described in Chapter IX., I compared them with those given above. In the case of copper, the oxygen-film variation is in the same direction as the temperature-variation of copper in air, which suggests the possibility of the latter being caused by an increase of the proportion of oxygen in the film at higher temperatures on account of a greater attraction between the elements. The same reasoning holds as regards zinc and tin, but the results for silver are in direct opposition: while the further experiments described in Chapter X., which show that the temperature-variations exist in cases where air is entirely exclnded from the metallic surface, render stich an explanation very doubtful. Probably, therefore, the temperature-variation is the more general of the two, it being a change in contact-potential of the metals, which, if they are exposed to a gas, may be complicated by alteration of the surface-film.

\section{Temperature Variations.}

$\$ 67$. A large number of determinations were made of the variation of contact-electricity with the temperature of the conductor. This was done by heating one plate while the other was kept cool, and their potential-difference was measured from time to time as the warm plate was cooling, their temperatures being observed at the same time. In the diagrams, the abscissæ represent temperature and the ordinates potential; each curve, therefore, shows the temperature-variation of the contact-potential of a particular metal. For instance, the potential represented by the point which corresponds to $16^{\circ} \mathrm{C}$. on the gold line is called zero in this and other chapters of the present communication. Thus a standard gold plate (see $\$ 8$ ) at $40^{\circ} \mathrm{C}$, is $\cdot 04 \mathrm{v}$. negative to one at $16^{\circ} \mathrm{C}$., and an aluminium plate at $40^{\circ} \mathrm{C}$. is $\cdot 10 \mathrm{v}$., positive to aluminium at $16^{\circ} \mathrm{C}$., or $1.20 \mathrm{v}$. positive to a gold plate at $16^{\circ} \mathrm{C}$.

It must be remembered that unless stated otherwise these variations are for metals in air. In the experiments described in Chapter X., however, the metallic surfaces were protected by solid non-conducting films, and were not in contact with the atmosphere; nevertheless, temperature-variations were found, which in the case of silver were actually larger than those which took place in air. 
$\S 68$. One of the copper plates used was hollow and could be filled with water and a thermometer inserted, but with the other plates other methods of measuring temperature had to be adopted. In some cases the temperature was measured thermo-electrically, while in others a simpler and more rapid mode of measurement was used, which, though not very accurate, is quite reliable within certain limits.

$\$ 69$. By touching the back of the plate I found that its temperature could be judged as "tepid," "slightly warm," "warm," "very warm," and so on. It was found experimentally that these terms correspond to constant temperatures; or rather that each term denotes a smill range of temperature, the middle point of which may be taken as corresponding to the term. In determining the values of these terms a plate was used in which a thermometer was inserted. One observer touched the plate with the tips of the first and second fingers and judged its state, naming it by one of the terms, "warm," "tepid," \&c., the other observed the thermometer, and the temperatures found to correspond to each term are as follows :-

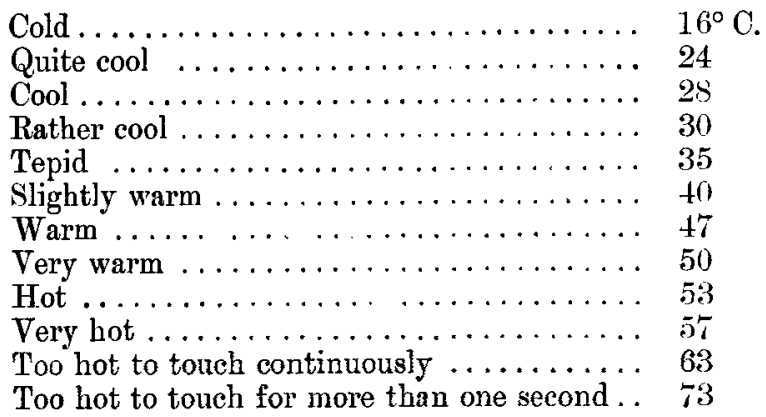

This method of measuring temperature is rongh and ready, but since the possible errors are witbin limits of a very few degrees, one only requires to take the average of a considerable number of results in order to arrive at a very fair approximation to the true values. In experiments on contact electricity in air there are so many possible causes of disturbance that extremely accurate measurement of the temperature is of little use, especially if it require that much time be spent over each reading.

$\S 70$. As a rule the upper plate was heated, in order that the lower plate might not be affected by draughts of hot air, as would have been the case if the lower had been hot and the upper cold. Sometimes, during the time of cooling, the upper part of the apparatus, including of course the upper 
plate, was removed after each observation and was replaced only the moment before the next. In other experiments the upper plate was merely drawn up as far as possible (about $10 \mathrm{~cm}$.) to prevent its warming the lower one. The temperature of the lower plate was also observed, but as a rule it varied only a very few degrees.

$\$ 71$. At first I used to apply a hot soldering-bolt to the back of the plate in order to heat it, but latterly I heated two or three small blocks of tinned copper and placed them on the back of the upper plate. By this second method it was possible to observe the variation of the potential during the rise as well as the fall of temperature.

$\$ 72$. In attempting to determine the temperature-coefficient of copper w'e were long baffled by curious anomalies. Sometimes the plate was positive when hot, other times negative, and occasionally it did not vary at all. The clue to this was found in observing that during one experiment while the copper was cooling it was at first positive, then negative, and then it gradually became positive again, though never quite reaching its original value.

Now it had been found that copper cxide is negative to copper, and that it became temporarily more negative when hot; hence it was guessed that the successively positive and negative variation must be due to hot clean copper being positive to cold copper, but that it had finally become oxidized and therefore negative whether hot or cold, the small permanent change being due to the thin coating of oxide formed.

$\$ 73$. The copper was heated much more gently next time, and gave the expected result that clean copper becomes rapidly more positive as its temperature rises, and that, on cooling, its potential returns to its original value unless the temperature has exceeded a certain limit. If this limit has been exceeded its potential rapidly becomes negative and does not return to its original value.

$\$ 74$. At ordinary atmospheric temperatures the surface of clean copper remains for a long time almost unaltered either visibly or electrically (see $\$ 31$ ), and the film which ultimately forms on the surface cannot be pure copper oxide because the potential of tarnished copper is higher than that of copper oxide obtained by heating in air. If, however, the temperature of the copper is raised to about $80^{\circ} \mathrm{C}$. it immediately begins to oxidize, though heating to a temperature below this limit does not rapidly produce any permanent change. Thus there is, as it were, an ignition point for copper and oxygen in air; below it, little action takes place; above it, combination proceeds vigorously. 
$\$ 75$. I shall now give a specimen experiment. The two standard gold plates gave

$$
-.02 \mathrm{v} .
$$

the minus sign indicating that the upper plate is negative. I now heated the upper ; when "tepid," i. e., about $35^{\circ} \mathrm{C}$, it gave with the cold plate

$-\cdot 045 \mathrm{v}$.

It was next heated further until "very hot" $\left(57^{\circ} \mathrm{C}.\right)$ and gave

$-\cdot 06 \mathrm{v}$.

When it had cooled down to "tepid" $\left(35^{\circ} \mathrm{C}.\right)$, it gave

When "cool" $\left(28^{\circ} \mathrm{C}.\right), \quad-.04 \mathrm{v}$.

Some hours later, when both plates were cold, they gave as at first

$$
-\cdot 02 \mathrm{v} \text {. }
$$

Hence the potential of gold which bas been washed with alcohol and allowed to dry falls temporarily about $.0016 \mathrm{v}$. per degree centigrade rise of temperature.

$\$ 76$. Most of the temperature experiments on copper were made with the hollow plite previously mentioned, which was filled with hot water in which the buib of a thermometer was placed. In many of the experiments on zinc, and also on aluminium, a thermo-electric arrangement was used, and the resnlts obtained with it do not differ materially from those obtained by the above method $(\$ 69)$. These and other details are noted on the diagram.

$\$ 77$. The diagram on p. 428 gives the temperature-variations of all the substances studied. The curves in it are plotted by taking the results for each metal of those experiments which are most free from all complication or cause of doubt. If the curves be prolonged in the direction of lower temperature they appear to meet somewhere below $-200^{\circ} \mathrm{C}$., and probably asymptotically to the line representing $4 \mathrm{v}$. positive to standard plate at $16^{\circ} \mathrm{C}$. Within their range they show contact-potential-differences diminishing with lowered temperature. The only apparent exceptions are clean copper, and silver coated with glass; but both their curves are distinctly bent between $16^{\circ} \mathrm{C}$. and $50^{\circ} \mathrm{C}$., so that probably they are directed towards the same point as the others at ower temperatures. Thus it appears that at about $-200^{\circ} \mathrm{C}$. the contact-potential-differences of metals may vanish, and 


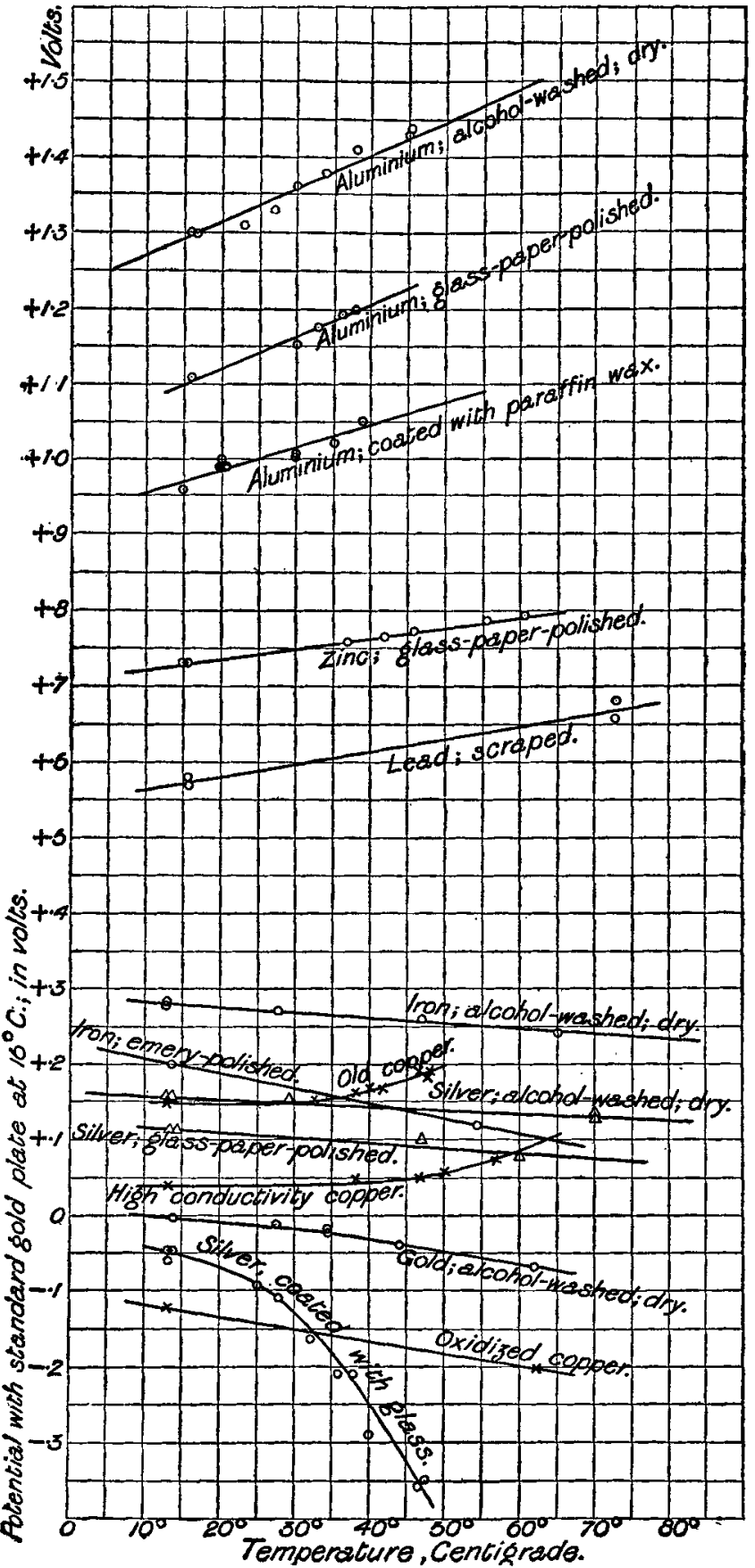


that a plate of any metal at that temperature would be about $\cdot 4$ volt positive to a standard gold plate at $16^{\circ} \mathrm{C}$.

$\S 78$. The approximate numerical values of the temperaturevariations are given in the following table:-

TABLF $\mathrm{V}$.

\begin{tabular}{|c|c|c|c|}
\hline Metal. & $\begin{array}{l}\text { Approximate } \\
\text { range of } \\
\text { Temperature. }\end{array}$ & $\begin{array}{c}\text { Potential of } \\
\text { metal with } \\
\text { standard } \\
\text { gold plate. } \\
\text { Both at } 16^{\circ} \mathrm{C} .\end{array}$ & $\begin{array}{c}\text { Variation of } \\
\text { potential per } 1^{\circ} \mathrm{C} . \\
\text { Standard plate kept } \\
\text { always at } 16^{\circ} \mathrm{C} .\end{array}$ \\
\hline 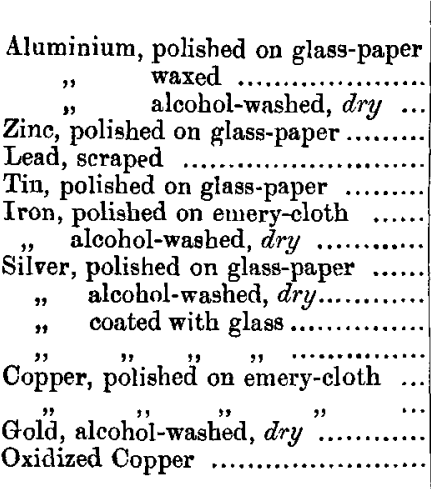 & $\begin{array}{r}{ }^{\circ} \mathrm{C} \\
16-50 \\
16-40 \\
16-47 \\
15-62 \\
16-75 \\
16-33 \\
16-55 \\
16-65 \\
16-60 \\
16-70 \\
16-30 \\
30-50 \\
16-30 \\
30-60 \\
16-60 \\
16-65\end{array}$ & 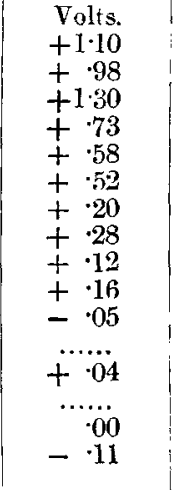 & \begin{tabular}{|r} 
Volts. \\
+.0043 \\
+.0032 \\
+.0045 \\
+.0013 \\
+.0016 \\
About -.0010 \\
-.0022 \\
-.0007 \\
-.0007 \\
-.0004 \\
About -.0035 \\
About -.0110 \\
Very small. \\
About +.0015 \\
-.0016 \\
-.0016
\end{tabular} \\
\hline
\end{tabular}

It must be clearly understood that these are true temperature-variations and not permanent changes in the plate caused by exposure to $x$ high lemperature.

\section{Elimination of Metal-Air Potentials by Solid Non- conducting Films on the Metallic Surfaces.}

$\S 79$. As very great differences of opinion seemed to exist as to the part played by the layer of air which is close to the metallic surface, I devised a method in which it should be removed and a film of solid non-conducting material of a very different chemical nature put in its place. A copper plate which had been polished on glass-paper was filed with a clean dry file which had not been used for any other metal. Its potential with the standard gold plate being

$$
+.045 \mathrm{v} \text {. }
$$

A zinc plate was prepared in an exactly similar way, and with the copper plate gave

$$
+\cdot 655 \mathrm{v} \text {. }
$$

Phil. Mag. S. 5. Vol. 45. No. 276. May 1898. 2 G 
The copper plate was now gently heated with a bolt until it was hot enough to melt paraffin-wax; the temperature, about $50^{\circ}$ C., required for this is not sufficient to cause sudden permanent change of the copper surface (see $\$ 74$ ). Paraffinwax was then poured on, and the plate was filed with its own file while covered with molten wax. Thus the fresh surface exposed by the filing came directly into contact with the wax. More wax was poured on and the filings drained off, the plate remaining well covered with wax all the while. It was then allowed to cool, and gave with the bare zinc plate

$$
+.555 \mathrm{v} \text {., }
$$

zine being positive as before. Thus the change due to substituting paraffin-wax for air next the copper is not more than $+\cdot 100$ v. I now waxed the zinc in exactly the same way. When it was quite cool it gave with the waxed copper

$$
+\cdot 602 \text { v., }
$$

showing that waxing the zinc had raised its potential

$$
+.047 \mathrm{r} \text {. }
$$

So on the whole, the substitution of wax for air on both copper and zinc had only decreased their mutual potential by

$$
+.053 \mathrm{v} \text {. }
$$

and the potential of the waxed plates remained nearly constant for several hours. The changes due to waxing the plates as given above were confirmed by the independent comparison of each plate with the standard gold plate. It does not follow that even the small changes which did occur were due solely to the substitution of wax for air, for they may have been caused by slight changes in the surface on account of the filing.

$\$ 80$. An aluminium plate was coated with wax in the way described in $\$ 79$, a knife being used to scrape the surface under the molten wax. When cold, this waxed plate gave with a bare zinc one

$$
+\cdot 36 \mathrm{v} \text {, }
$$

which is about the usual value for bare aluminium and zinc. The removal of the air had therefore not appreciably altered the potential.

$\$ 81$. I now warmed the waxed aluminium slightly. Its potential with the zinc varied as follows:-

$$
\begin{aligned}
& 47^{\circ} \mathrm{C} \text {. . . . + }+41 \mathrm{v} \text {. } \\
& 35^{\circ} \mathrm{C} . .+.+{ }^{\circ} 37 \mathrm{v} \text {. } \\
& 28^{\circ} \mathrm{C} \text {. . . + }+35 \mathrm{v} \text {. }
\end{aligned}
$$


This gives a variation of about

.0032 v. per degree centigrade,

which is nearly the same as the temperature-variation of bare aluminium in air.

$\$ 82$. A plate of silvered glass used with the glass side facing a standard plate gave almost the same potential as clean silver in air. This plate, which was practically silver coated with glass, gave a temperature-variation larger than that of silver in air. In this case we have glass in contaet with the silver surface instead of air, but the change does not alter the potential. It may be mentioned that the back of the silver film was painted black, and not coated with glass; but this is of small consequence, since it has been proved by experiment that the condition of the back of a plate does not sensibly affect the volta contact-potential; or, more generally, that if parts of a plate be in different conditions, the potential observed will be the mean of the potentials of the different parts, the importance of each part being proportional to its capacity.

\$83. On account of the great attraction of sodium for oxygen, it seemed of interest to measure its potential in circumstances which excluded that gas from the surface of the metal. In order to effect this two pieces of thin sheet-glass, each about $6 \mathrm{~cm}$. square, were put into a dish of melted paraffin-wax together with some clean sodium, and a large drop of the sodium was put between the plates of glass and squeezed out into a small plate of 3 or 4 square $\mathrm{cm}$. area. The glass plates, with sodium between them, were taken out of the melted wax and allowed to cool. Since the glass plates were of much larger diameter than the sodium, the edges of the latter were protected by the wax which filled up the space between the plates not occupied by sodium. The flat faces of the sodium were apparently in contact with the glass. The sodium was connected to the electrometer by a fine copper wire. The greater part of the sodium surface was bright or only slightly tarnished, and it remained in almost the same condition for many days, being protected by the glass plates and by the wax which filled the space between them unoccupied by sodium. The first measurements gave sodium

$2 \cdot 86 \mathrm{v}$

positive to a tarnished zinc plate, i. e. about

$3.56 \mathrm{v}$.

positive to the standard gold plate. This potential gradually decreased. 
$\$ 84$. Experiments were made to make sure that the result. was not due to temporary electrification of the glass. For instance I breathed on the glass, causing a conducting layer of impure water to form on its surface. Repeated measurements, made by the usual method, showed that the potential at once fell to a small fraction of a volt, but slowly rose again to nearly its original value as the film evaporated. This shows that the electrification was not a temporary one of the glass surface, for that would not have returned to a definite value. Heating the plate by radiation or washing the glass with benzol caused the potential 10 rise further, but in no case was the potential quite so high as when the plate was first formed. An even more convincing proof that the potential mensured was really that of the sodium was found in the fact that the sensibility of the apparatus was such as would be given by a plate the size of the sodium. If the electritication had been on the whole surface of the glass, the sensibility, on account of the larger surface, would have been at least ten times as great as that obsorved.

$\$ 85$. The experiments described in this chapter show that (i.) when two metals are coated with the same non-conductor, such as wax or glass, their potential is not sensibly different from that of the bare metals in air ; (ii.) that temperaturevariation still takes place, though air be excluded. 'These results seem to prove that gaseous films play no essential part in the phenomenon.

XLIV. On the Susceptilility of Diamagnetic and Weakly Magnetic Substances. By Albert P. Wills*.

FARADAY (1845) showed that all substances, whether solid, liquid, or gaseous, are either diamagnetic or magnetic. Previously, however, Brugmans (1778) and Becquerel (1827) observed certain diamagnetic phenomena.

$\mathrm{By}$ way of relative measurement of the coefficient of susceptibility, a great deal has been done by various physicists, among them Plücker and Faraday. For bismuth there have been a number of determinations in absolute measure. It will suffice to mention here four of the best methods used : -1 . The method used by Christiet (1858) depends upon the comparison of the inductive action of the magnetized bismuth with that of a solenoid through which a known current is flowing. 2. The method used by Töpler

* Communicated by Prof. A. G. Webster.

$\dagger$ Porg. Ann. ciii. p. 577 (1858). 